\title{
Article \\ Effect of Micro- and Macro-Mechanical Characteristics of Jujube Bark on Jujube Girdling Quality
}

\author{
Junhui Ran ${ }^{1,2,+}$, Can Hu ${ }^{1,2,3,+}$, Fengkui Zhang ${ }^{1,2}$, Xufeng Wang ${ }^{1,2, *}$ and Ping $\mathrm{Li}^{1,2}$ \\ 1 College of Mechanical and Electrical Engineering, Tarim University, Alar 843300, China;

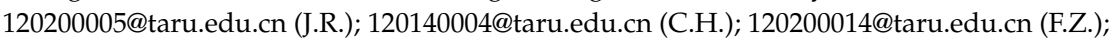 \\ 119980015@taru.edu.cn (P.L.) \\ 2 Agricultural Engineering Key Laboratory, Ministry of Higher Education of Xinjiang Uygur Autonomous \\ Region, Tarim University, Alar 843300, China \\ 3 College of Engineering, China Agricultural University, Beijing 100083, China \\ * Correspondence: 119990012@taru.edu.cn \\ + These authors contributed equally to this work.
}

Citation: Ran, J.; Hu, C.; Zhang, F.; Wang, X.; Li, P. Effect of Micro- and Macro-Mechanical Characteristics of Jujube Bark on Jujube Girdling Quality. Agriculture 2022, 12, 278. https://doi.org/10.3390/ agriculture12020278

Academic Editors: Zhichao $\mathrm{Hu}$ and Fengwei $\mathrm{Gu}$

Received: 27 December 2021 Accepted: 10 February 2022 Published: 15 February 2022

Publisher's Note: MDPI stays neutral with regard to jurisdictional claims in published maps and institutional affiliations.

Copyright: (C) 2022 by the authors. Licensee MDPI, Basel, Switzerland. This article is an open access article distributed under the terms and conditions of the Creative Commons Attribution (CC BY) license (https:// creativecommons.org/licenses/by/ $4.0 /)$.

\begin{abstract}
Jujube girdling is an important method to improve the yield and quality of jujube fruit. However, girdling usually causes the tearing of jujube bark, resulting in the slow healing and even death of jujube trees. These problems directly affect the economic benefits of jujube planting. In this paper, in order to reveal the tearing mechanism of jujube bark caused by girdling, and provide the basic mechanical parameters of jujube bark for the research and development of automatic girdling equipment, the structure and mechanical characteristics of jujube bark were studied through theory and experimental methods. The results of microscopic observation showed that jujube bark is a biological composite material mainly composed of the phloem, periderm and epidermis. Furthermore, a mathematical model-based analysis of the growth stress of jujube bark showed that growth stress can be regarded as a biaxial stress state, which can promote the longitudinal tearing of jujube bark during girdling. The tensile test results of jujube bark showed that jujube bark belongs to the category of anisotropic and biologic material. Its longitudinal and transverse mechanical characteristics are significantly different. The maximum longitudinal tensile load was in the range of 105.9 293 N, the longitudinal tensile strength was 16.3 MPa and the elastic modulus was 255.6 MPa. The average transverse tensile load was only $27.9 \%$ of the longitudinal tensile load. The transverse tensile strength was 3.5 Mpa and its elastic modulus was $724.14 \mathrm{MPa}$. The transverse cutting test of jujube bark showed that the average cutting force was $118.2 \mathrm{~N}$ and the cutting strength was 9.8 MPa. The results of this study showed that both the growth stress and the anisotropic natural polymer of jujube bark have adverse effects on girdling. Subsequently, issues relating to the selection of appropriate girdling tools and the matters needing attention in the process of the girdling operation were proposed, so as to guide the correct application of girdling technology. In addition, some suggestions on the research and development of girdling tools in the future are put forward.
\end{abstract}

Keywords: jujube girdling; mechanical properties; composite material; growth stress; bark

\section{Introduction}

Jujube is rich in nutrition, containing extremely high ascorbic acid, a variety of amino acids, and dozens of mineral elements, sugars, phenols and other nutrients, so it is deeply loved by consumers [1-3]. The jujube planting area in China accounts for more than $98 \%$ of the total jujube cultivation area in the world, and the jujube planting area in Southern Xinjiang alone is about $5 \times 10^{5} \mathrm{hm}^{2}$ [4]. Jujube planting has become the pillar of the fruit industry in southern Xinjiang and the main economic source of orchard workers [5]. Although jujube trees produce many flowers in the natural growth state, the flower drop rate is more than $98 \%$ [6]. In order to improve the yield of red jujube, most varieties such as Hui jujube and winter jujube need to be girdled at the stage of $40 \%$ full flowering [7]. 
Girdling refers to peeling off a circle of the bark from the phloem to the epidermis without harming the xylem on the trunk or branch of jujube with a knife, temporarily cutting off the downward transportation of nutrients in the tree, so as to meet the nutrient needs of flowering and fruit setting, thereby promoting fruit setting [8]. Practice shows that proper girdling can not only significantly promote its yield [9-15], but also improve the quality of jujube fruit, increasing the content of soluble solids, total sugar and Vitamin C in jujube fruit [16]. However, it is easy to cause jujube bark tear ("Bark tear" means the bark at the edge of the wound is torn along its fiber direction, that is to say, girdling destroys the bark around the wound), so the girdling wound cannot heal normally or even the tree die when it is girdled. The girdling wound that does not heal in time can easily provide spawning places for pests, resulting in reduced production of fruit trees, and so on. Therefore, it is of great significance for the sustainable development of the jujube planting industry to find out the reasons for the tearing of jujube bark in the process of girdling in order to reduce the adverse effects of girdling.

There are many reasons why the bark of jujube is easy to tear during girdling; for example, it happens when the epidermis or phloem are not cut off properly because of the blunt girdling knife or the operator's use of the wrong operation, and so on. However, as a typical anisotropic natural polymer material [17-19], how the extremely complex physical and mechanical characteristics of jujube bark affect the quality of jujube girdling is unknown. Furthermore, in the natural state, there are numerous longitudinal cracks in the surface of jujube bark, which are generally believed to be caused by growth stress. Since the jujube bark is easy to tear along the direction of fiber arrangement in the process of girdling, the jujube bark growth stress may be one of the reasons for the bark tear in the girdling process. At present, the research work on the girdling of fruit trees mainly focuses on the impact of girdling on the fruit yield, quality and the physiological influence of the fruit tree. However, there are few literature studies on the cause of bark tear during girdling and the mechanical properties of bark [20-22]. Therefore, it is necessary to research the physical and mechanical characteristics and growth stress distribution of jujube bark to explore how they affect jujube girdling, and obtain the relevant mechanical characteristic parameters of the bark, in order to guide the jujube girdling technology and provide a basis for the design of girdling machines.

Thus, in this study, the growth stress and mechanical characteristics of jujube bark were studied. In order to ascertain the composition and structure of jujube bark in order to provide basic theorical evidence for the study of growth stress, the cross section of jujube bark was observed by microscope in advance. The cross-section of a jujube trunk was magnified 200 times and the results are shown in Figure 1a,b. The jujube bark is connected to the xylem by the phloem and consists mainly of three parts: the phloem, periderm and outer epidermis. Studies $[23,24]$ have shown that both the xylem and phloem are generated by cambium cells through cell division and differentiation. In this process, primordial cells undergo a biomechanical transformation process that causes the cell to change in size with maturation. According to the literature [23], with new cells continuously attached to the surface of existing wood materials, this deformation no longer develops freely, but generates tensile stress along the axial direction and compressive stress in the tangential direction in the newly grown external wood materials. This kind of stress generated near the cambium leads to the stress distribution law on the cross section of its trunk, as shown in Figure 1c. It can be seen from the figure that trees bear compressive stress within $2 / 3$ of the radius of the cross section. Beyond $2 / 3$ of the radius of the cross section, the tree bears tensile stress, and the bark at the outermost layer of the cross section bears the maximum tensile stress.

Based on the above structural characteristics and growth stress properties of jujube bark, the mechanical model of jujube bark growth stress was constructed. Based on the growth stress model, the distribution of growth stress in the natural state of jujube bark and the mechanism of its influence on jujube girdling were theoretically analyzed in this paper. Furthermore, the longitudinal and transverse tensile tests, and the transverse cutting test 
of jujube bark were carried out, and the anisotropic mechanical parameters of bark were obtained. The ways in which the anisotropic mechanical properties of jujube bark influence jujube girdling were analyzed.

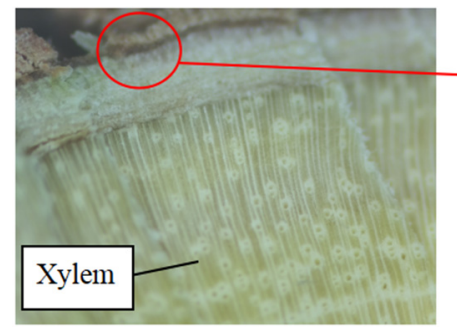

(a)

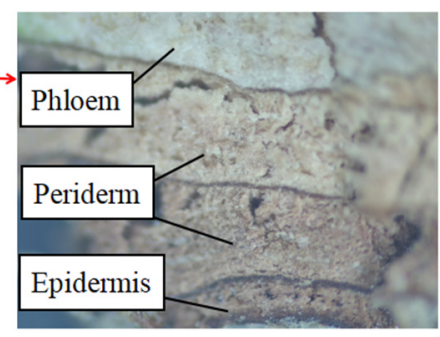

(b)

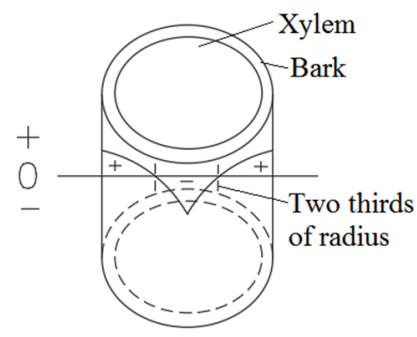

(c)

Figure 1. Structure of jujube bark under microscope and distribution law of tree growth stress: (a) microstructure of jujube trunk in cross-section under microscope; (b) microstructure of jujube bark in cross-section; (c) distribution law of tree growth stress, "+" represents the tensile stress area and "-" represents the compressive stress area.

\section{Materials and Methods}

\subsection{Materials}

The jujube bark samples were taken from the jujube garden in Alar, Southern Xinjiang, on 15 June 2021. When the jujube trees were in the optimal girdling period, straight and healthy jujube trunks were selected from 6 trees to be cut off and brought back to the laboratory to quickly determine their physical parameters. The measured parameters of jujube bark are shown in Table 1.

Table 1. Physical parameters of jujube bark.

\begin{tabular}{|c|c|c|c|c|}
\hline Number & $\begin{array}{l}\text { Diameter of } \\
\text { Trunk (mm) }\end{array}$ & $\begin{array}{c}\text { Thickness of } \\
\text { Bark (mm) }\end{array}$ & $\begin{array}{c}\text { Moisture Content } \\
\text { of Bark (\%) }\end{array}$ & $\begin{array}{c}\text { Density of } \\
\text { Bark }\left(\mathrm{g} \cdot \mathrm{cm}^{-3}\right)\end{array}$ \\
\hline 1 & 17.68 & 1.17 & 55.78 & 0.69 \\
\hline 2 & 20.82 & 1.66 & 54.23 & 0.65 \\
\hline 3 & 25.32 & 1.75 & 61.49 & 0.82 \\
\hline 4 & 32.51 & 2.25 & 55.92 & 0.71 \\
\hline 5 & 36.22 & 2.58 & 57.22 & 0.78 \\
\hline 6 & 41.12 & 3.16 & 53.44 & 0.61 \\
\hline Average value & 28.94 & 2.09 & 56.34 & 0.71 \\
\hline Standard deviation & 8.36 & 0.65 & 2.60 & 0.07 \\
\hline
\end{tabular}

The longitudinal tensile test samples were made with the size of $100 \mathrm{~mm}$ in length and $10 \mathrm{~mm}$ in width, as shown in Figure 2. The transverse tensile test samples were made with the size of $20 \mathrm{~mm}$ in length and $10 \mathrm{~mm}$ in width. The samples used in the transverse cutting experiment were $50 \mathrm{~mm}$ in length and $10 \mathrm{~mm}$ in width. In every test, each unique sample was used three times, and the results were averaged. The length direction of all samples was consistent with the direction of the bark fiber.

\subsection{Methods}

\subsubsection{Bark Growth Stress Modeling}

The structure and shape of bark wrapped on the trunk are complex, but this study focused on the influence of growth stress on bark, so some fine structures of bark needed to be ignored to enable convenience in terms of the modeling and analysis of the main problems [25]. Firstly, the cross section of the bark on the trunk was approximately regarded as a circle. Secondly, the cross-sectional diameter was different along the height of the tree, but the change of this cross-section size compared with the tree height was so small that it could be ignored. Therefore, it was considered that the cross-section diameter of bark 
on the trunk remained unchanged. In addition, jujube bark is a type of biomaterial and has viscoelastic properties. In order to facilitate modeling and analysis, jujube bark was regarded as an ideal elastomer. Based on the above assumptions, and the position height $\mathrm{Z}$ of the tree relative to the ground, the xylem diameter $\mathrm{D}$ and the corresponding bark thickness $t$ were taken as direct variables of growth stress, and the mechanical model of jujube bark growth stress was regarded as a thin-walled elastic cylinder with inner wall compression (details are shown in Figure 3). As shown in Figure 3a, the pressure caused by the growth stress in the height direction of the jujube on the thin-walled cylinder was represented by $P$, and the pressure caused by the circumferential growth stress of the jujube was denoted with $P_{(z)}$.

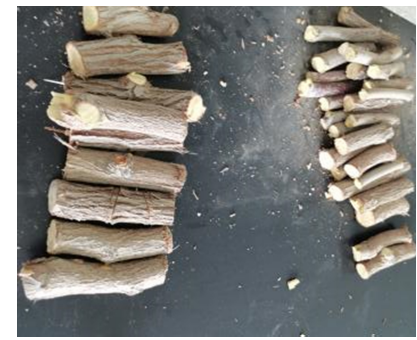

(a) Jujube trunks for making bark samples.

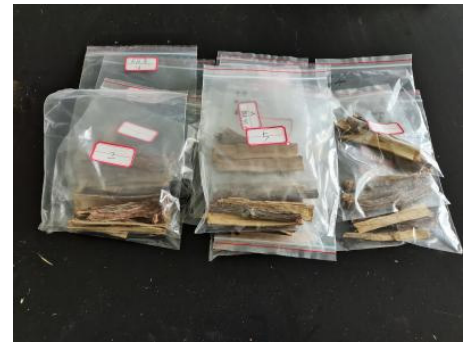

(b) Jujube bark samples for longitudinal tensile test.

Figure 2. Longitudinal tensile test samples of jujube bark.

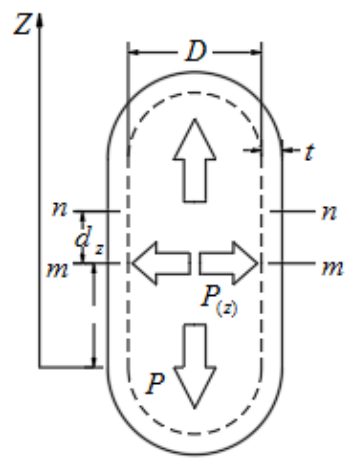

(a) Growth stress model of jujube bark.

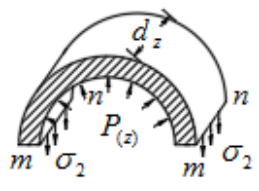

(c) Longitudinal section stress state of jujube bark.

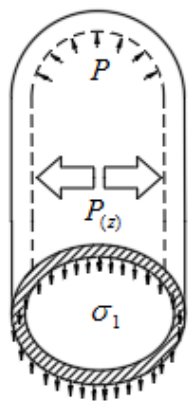

(b) Cross section stress state of jujube bark.

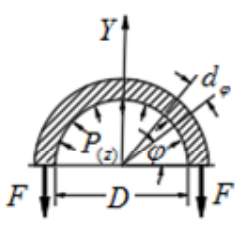

(d) Longitudinal section stress analysis of jujube bark.

Figure 3. Simplified growth stress model of jujube bark. Note: In Figure (a), $Z$ is the axial ordinate of jujube, $\mathrm{mm}$; $P$ is the axial growth pressure of jujube bark, $\mathrm{MPa} ; P_{(z)}$ is the pressure caused by the circumferential growth stress of jujube bark, $\mathrm{MPa}$; $D$ is the xylem diameter of jujube, $\mathrm{mm}$; $t$ is the thickness of jujube bark, mm; $m-m$ and $n-n$ are cross sections, and $d_{z}$ is the distance between the two cross sections, mm. In Figure (b), $\sigma_{1}$ is the axial growth stress of jujube bark, MPa. In Figure (c), $\sigma_{2}$ is the growth stress of the longitudinal section of jujube bark, MPa. In Figure (d), $F$ is the resultant force of the longitudinal section stress, $N ; \varphi$ is the arc angle of the cross section, rad; $d_{\varphi}$ is the arc's differential element. 


\subsubsection{Tensile Test of Jujube Bark}

The WD-D3-7 microcomputer controlled electronic universal testing machine produced by Shanghai Zhuoji Instrument and Equipment Co., Ltd. (Shanghai, China) was adopted as the mechanical testing equipment, with a testing force range of $2 \mathrm{kN}$, as shown in Figure 4a. The error of the force sensor and displacement sensor of the equipment was less than $\pm 0.5 \%$. In order to prevent the damage of the test materials from the fixture, both ends of the samples were wrapped with gauze [26-28]. The tensile test consisted of longitudinal and transverse tensile tests [29]. The loading speed of the test was $10 \mathrm{~mm} / \mathrm{min}$. In order to avoid the error caused by the instability of the initial state of the test, the elastic modulus was calculated based on the ratio of the increment of the stress to that of the strain, as shown in Equation (1). The tensile strength of jujube bark was calculated through Equation (2).

$$
E=\frac{\Delta \sigma}{\Delta \varepsilon}=\frac{F_{n}-F_{0}}{b t\left(\varepsilon_{n}-\varepsilon_{0}\right)}
$$

where $E$ is the elastic modulus, $\mathrm{MPa} ; \Delta \sigma$ is the stress increment, $\mathrm{MPa} ; \Delta \varepsilon$ is the strain increment; $F_{0}$ and $F_{n}$ are the initial load and final load, respectively, $\mathrm{N} ; \varepsilon_{0}$ and $\varepsilon_{n}$ are the initial strain and final strain, respectively; $b$ is the width of the sample, $\mathrm{mm}$; $t$ is the thickness of the sample, $\mathrm{mm}$.

$$
\sigma=\frac{F_{\max }}{b t}
$$

where $\sigma$ is the tensile strength, $\mathrm{MPa} ; F_{\max }$ is the maximum tension, $\mathrm{N} ; b$ is the width of the sample, $\mathrm{mm}$; $t$ is the thickness of the sample, $\mathrm{mm}$.

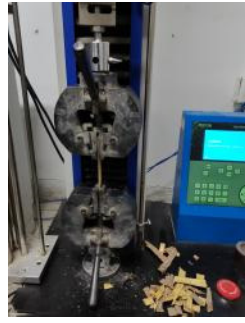

(a)

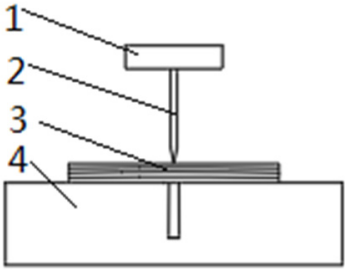

(b)

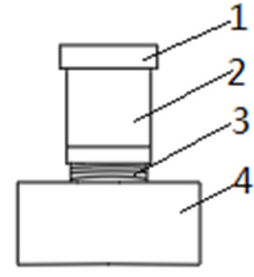

(c)

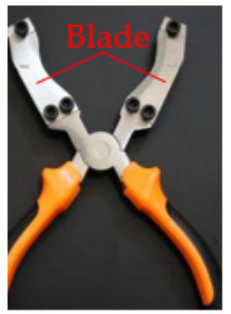

(d)

Figure 4. Equipment and platform for mechanical testing of jujube bark: (a) universal testing machine; (b) front view of the cutting test platform; (c) side view of the cutting test platform; (d) structure of the cutter blade used for the cutting test. 1. Blade fixture. 2. Cutter blade. 3. Jujube bark. 4. Support platform.

\subsubsection{Transverse Cutting Experiment of Jujube Bark}

Because the bark of the jujube is cut off in the transverse direction during girdling, in order to simulate this situation, the transverse cutting method was adopted in this test. During the test, the outer surface of the jujube bark was on top, and the fiber direction of jujube bark was perpendicular to the blade. The schematic diagram of the cutting test platform is shown in Figure $4 b, c$. Furthermore, the smooth-edge stainless steel blade with a blade angle of $20^{\circ}$, which is widely used in jujube girdling, was used in this cutting experiment (Figure $4 \mathrm{~d}$ ).

Equation (3) was used for the calculation of the cutting strength of the jujube bark.

$$
\tau=\frac{F_{\tau \max }}{A}
$$

where $\tau$ is the shear strength, $\mathrm{MPa} ; F_{\tau \max }$ is the maximum shear load, $\mathrm{N} ; A$ is the shear area, $\mathrm{mm}^{2}$. 


\section{Results and Analysis}

\subsection{Results of Growth Stress Model Analysis of Jujube Bark}

According to Figure $3 \mathrm{~b}$, the axial mechanical balance equation of the thin-walled cylinder, based on the static balance method, is as follows:

$$
p \cdot \pi\left(\frac{D}{2}\right)^{2}=\sigma_{1} \cdot \pi \cdot D \cdot t
$$

The axial growth stress of jujube bark obtained by solving the above equation is shown in Equation (5). It can be seen that the axial growth stress of jujube bark is related to the expansion pressure $\mathrm{P}$ at the top of the jujube, and the expansion pressure depends on the growth rate of the jujube. It is also positively correlated with the ratio of xylem diameter $\mathrm{D}$ to bark thickness t. Because the growth rate of xylem is always faster than that of jujube bark, it can be considered that the thicker the trunk, the greater the axial tensile stress on the bark. That is, the axial growth stress of jujube bark near the ground is the largest.

$$
\sigma_{1}=\frac{p D}{4 t}
$$

A part of the cylinder was intercepted with two sections ( $m-m$ and $n-n$ at a distance of $d_{z}$ ) and a longitudinal plane including the diameter to obtain the part shown in Figure 3c. According to the stress characteristics of the longitudinal section of jujube bark in Figure $3 \mathrm{~d}$, the mechanical balance Equation (6) could be obtained:

$$
\int_{0}^{\pi} p_{z} d_{z} \cdot \frac{D}{2} \sin \phi d_{\phi}-2 \sigma_{2} t d_{z}=0
$$

By solving the above formula, the longitudinal section stress $\sigma_{2}$ of jujube bark was obtained, as shown in Equation (7). Generally, the circumferential growth rate of the jujube trunk nearest to the ground is still the largest. According to Equation (7), the stress on the longitudinal section of jujube bark was also the largest. Therefore, the bark on the trunk of the jujube close to the ground had the maximum cross-section growth stress and longitudinal-section growth stress. There were a large number of wide and deep growth cracks on the bark of jujube near the ground. Therefore, the conclusion of this analysis is consistent with the actual situation.

$$
\sigma_{2}=\frac{P_{(z)} D}{2 t}
$$

If the radial stress of jujube bark was ignored, it can be concluded from the above analysis that the differential element body that was $Z$ away from the ground on jujube bark was in a biaxial stress state.

\subsection{Tensile Test Results of Jujube Bark}

\subsubsection{Longitudinal Tensile Test Results of Jujube Bark}

The results of longitudinal tensile test are shown in Figure 5. It can be seen from Figure 5 a that the maximum load that the jujube bark could bear in different test groups was significantly different, and the load was in the range of 105.9 293.1 N. However, their yield load was basically the same, about $70 \mathrm{~N}$. The calculation results showed that the longitudinal tensile strength was $16.3 \mathrm{MPa}$ and the elastic modulus was $255.6 \mathrm{MPa}$. In addition, the variation law of the load-displacement curve of each group of tests was consistent. As shown in Figure 5b (average longitudinal tensile load), each load-displacement curve of tensile tests can be divided into three stages. From the beginning of the test to point A was the initial stage, practically the elastic deformation stage, and the load was basically linearly and positively correlated with the deformation. The second stage from A to B was a yield process. In this stage, the load changed little with the continuous increase in 
displacement. In the third stage from B to $C$, jujube bark was strengthened and restored its ability to resist deformation. The load increased approximately linearly with the increase in deformation, and the increase rate was greater than that of the first stage until the sample was pulled apart.

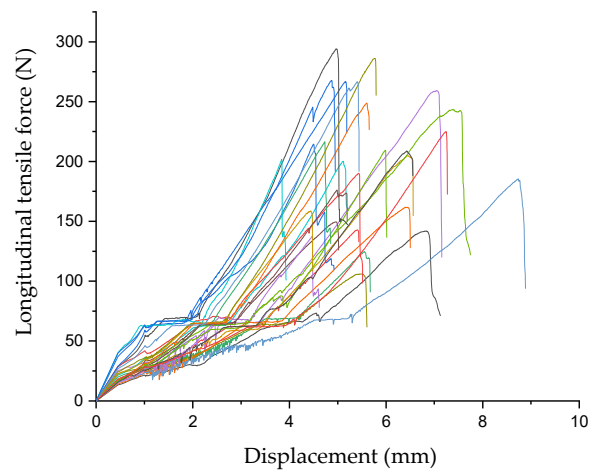

(a) Longitudinal tensile load-displacement curve.

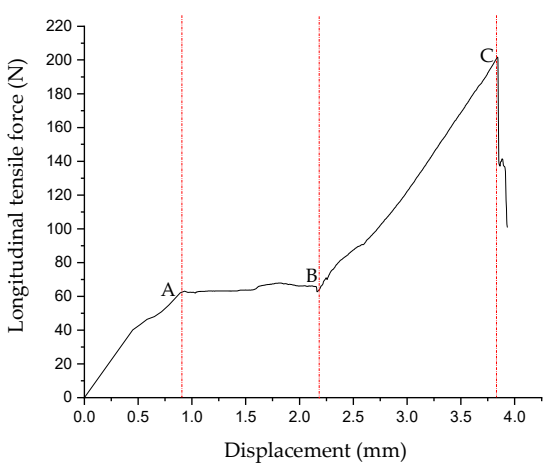

(b) Characteristics of longitudinal tensile load curve.

Figure 5. Longitudinal tensile test results: A is approximately the dividing point between elastic stage and yield stage; $\mathrm{B}$ is approximately the dividing point between yield stage and strengthening stage; $\mathrm{C}$ is the point of tensile strength.

In order to observe the concentration, dispersion and distribution of extreme data of each group of tests, and to analyze the functional relationship between the maximum longitudinal tensile force of jujube bark and the corresponding diameter, the boxplot and data fitting line of the maximum tensile force were drawn (Figure 6). It can be seen from the boxplot (Figure 6a) that the Inter-Quartile Range (IQR) was small and there was no abnormal value, indicating that the data of each group of tests were relatively centralized. That is, the mechanical properties of jujube bark along the longitudinal direction were stable under the same natural state. According to the data fitting line of the maximum tensile force shown in Figure 6b, the maximum tensile load along the longitudinal direction of jujube bark was positively correlated with its corresponding trunk diameter. Furthermore, the determination coefficient $R^{2}$ was 0.929 , indicating that the fitted function had a high degree of fitting to the actual data. The fitting function is shown in Equation (8).

$$
y_{2}=5.873 x_{2}+17.031
$$

where $y_{2}$ is the tensile force of the jujube bark, $\mathrm{mm} ; x_{2}$ is the corresponding diameter of the jujube tree, $\mathrm{mm}$.

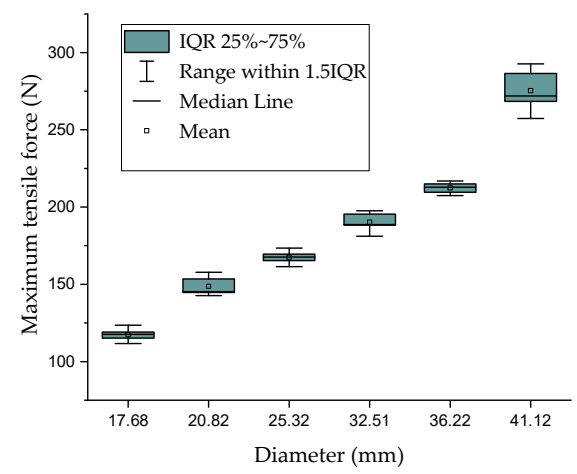

(a) Boxplot

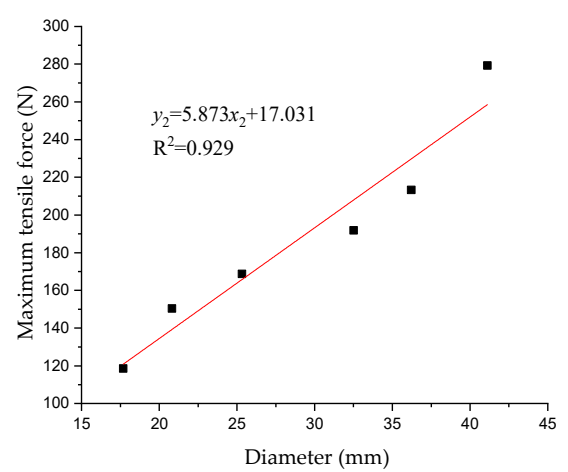

(b) Fitting function

Figure 6. Boxplot and fitting function of longitudinal maximum tensile force. 


\subsubsection{Transverse Tensile Test Results of Jujube Bark}

The transverse tensile test results of jujube bark are shown in Figure 7; these were significantly different from the results of the longitudinal tensile test. As shown in Figure 7a, the maximum transverse tensile load was $84.4 \mathrm{~N}$ and the minimum was $28.6 \mathrm{~N}$, which was only $27.9 \%$ of the average longitudinal tensile load. The transverse tensile strength was $3.5 \mathrm{Mpa}$, and the elastic modulus was $724.14 \mathrm{Mpa}$, which was about 3.21 times the longitudinal tensile elastic modulus. It can be seen from Figure $7 \mathrm{~b}$ (average transverse tensile load) that from the initial position of the test to point A was the approximate elastic stage of the transverse tensile load-displacement curve, and its slope was significantly greater than that of the corresponding stage in the longitudinal tensile test. The second stage $\mathrm{AB}$ was the transverse tensile yield process of the jujube bark, and the yield curves of different test groups were highly consistent in curve shape. In the third stage (from B to C), the load continued to rise in an approximate straight line with the deformation until the jujube bark load reached the transverse tensile limit and was pulled apart.

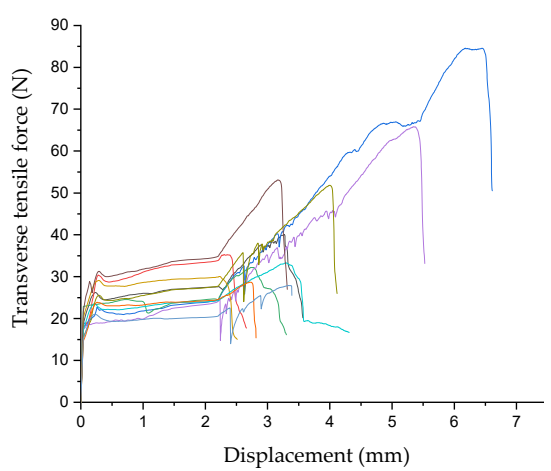

(a) Transverse tensile load-displacement curve.

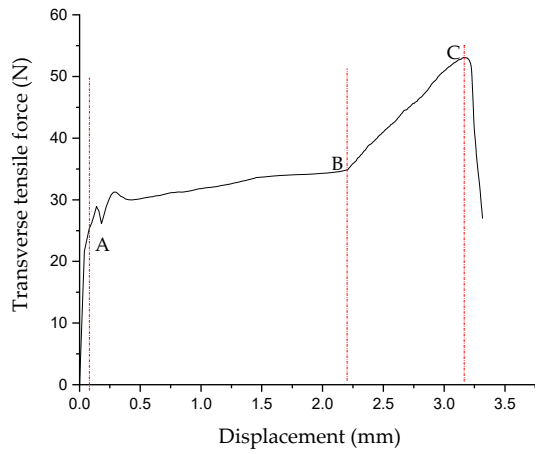

(b) Characteristics of transverse tensile load-displacement curve.

Figure 7. Transverse tensile test results of jujube bark: $A$ is approximately the dividing point between elastic stage and yield stage; $\mathrm{B}$ is approximately the dividing point between yield stage and strengthening stage; $C$ is the point of tensile strength.

The boxplot and data fitting line of the maximum tensile force test results of transverse tensile load-displacement were drawn (Figure 8). It can be seen from the boxplot (Figure 8a) that the IQR was small and there was no abnormal value, indicating that the data of each group of tests were relatively centralized. That is, the transverse tensile mechanical properties of jujube bark were stable under the same natural state. According to the data fitting line of the maximum transverse tensile force shown in Figure 8b, the maximum tensile load along the transverse direction of jujube bark was positively correlated with its corresponding trunk diameter. And the determination coefficient $R^{2}$ was 0.988 , indicating that the fitted function had a high degree of fitting to the actual data. The fitting function is shown in Equation (9).

$$
y_{3}=2.262 x_{3}-14.662
$$

where $y_{3}$ is the tensile force of the jujube bark, $\mathrm{mm} ; x_{3}$ is the corresponding diameter of the jujube trunk, $\mathrm{mm}$.

\subsection{Transverse Cutting Test Results of Jujube Bark}

Figure 9 shows the results of the transverse cutting test of jujube bark, and the average maximum cutting force was $118.2 \mathrm{~N}$. It can be seen from Figure 9a that the deformation of the samples during transverse cutting was small. As shown in Figure $9 \mathrm{~b}$ (average transverse cutting load), the yield stage (approximately from A to B) was short. When the cutting force was achieved at point $C$ (the jujube bark strength limit point), the bark was cut. The average cutting strength of the jujube bark was calculated to be $9.8 \mathrm{MPa}$. 


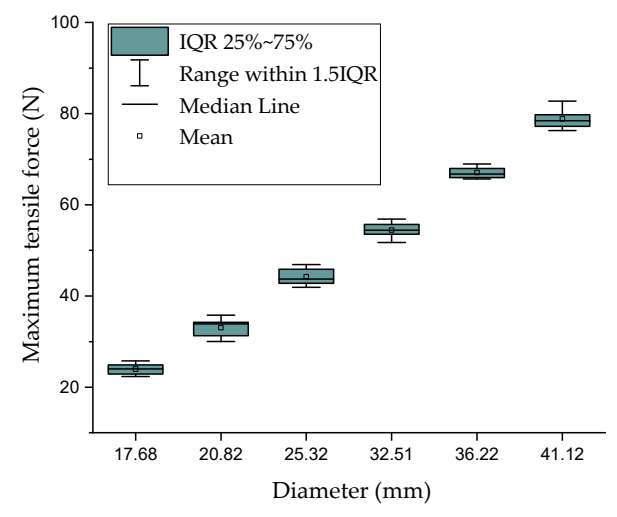

(a) Boxplot

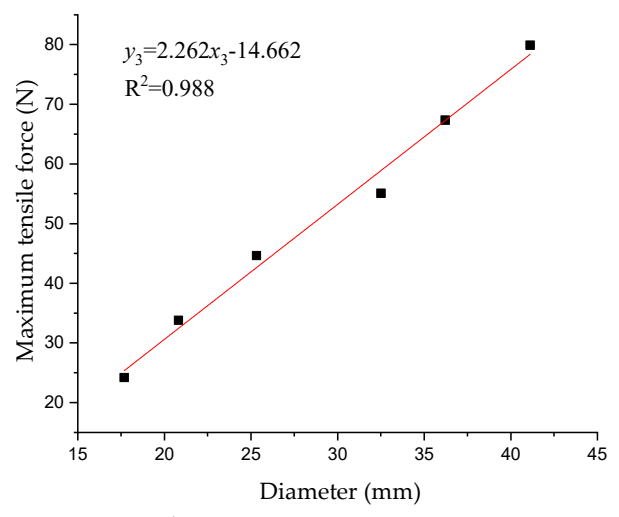

(b) Fitting function

Figure 8. Boxplot and fitting function of transverse maximum tensile force.

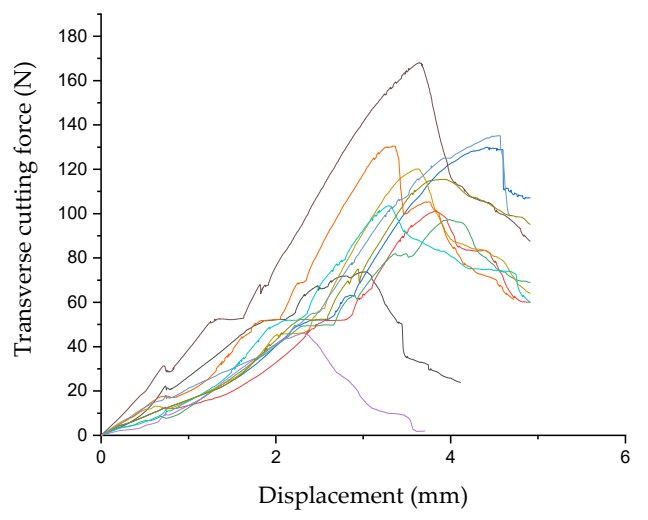

(a) Transverse cutting load-displacement curve.

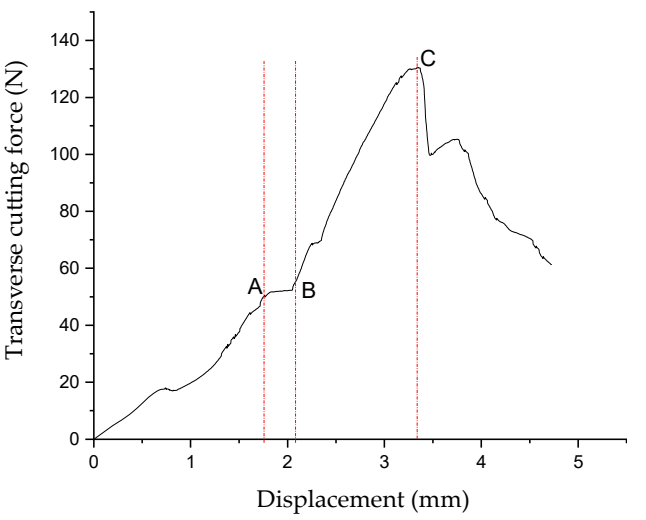

(b) Characteristics of transverse cutting load-displacement curve.

Figure 9. Results of transverse cutting test: A is approximately regarded as the dividing point between elastic stage and yield stage; B is approximately regarded as the dividing point between yield stage and strengthening stage; $C$ is approximately regarded as the point of tensile strength.

The boxplot and data fitting line of the maximum transverse cutting load-displacement of jujube bark were drawn, as Figure 10 shows. It can be seen from the boxplot (Figure 10a) that the IQR was small and there was no abnormal value, indicating that the data of each group of tests were relatively centralized. That is, the mechanical properties of the transverse cutting of jujube bark were stable under the same natural state. According to the data fitting line (Figure 10b), the maximum transverse cutting load of jujube bark was positively correlated with its corresponding trunk diameter. Furthermore, the determination coefficient $\mathrm{R}^{2}$ was 0.961 , indicating that the fitted function had a high degree of fitting to the actual data. The fitting function is shown in Equation (10).

$$
y_{4}=4.178 x_{4}-14.022
$$

where $y_{4}$ is the maximum cutting force, $\mathrm{N} ; x_{4}$ is the diameter of the jujube, $\mathrm{mm}$. 


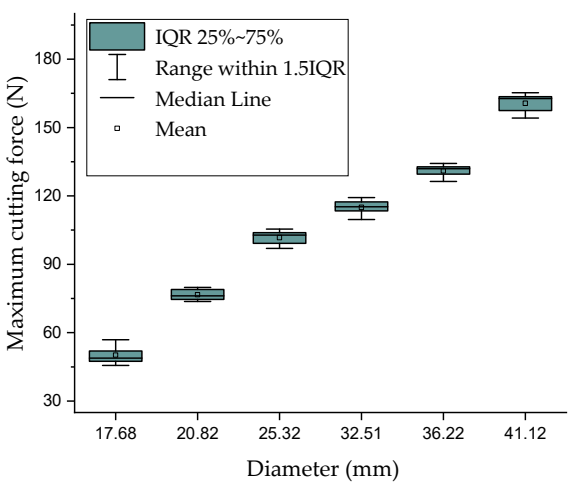

(a) Boxplot.

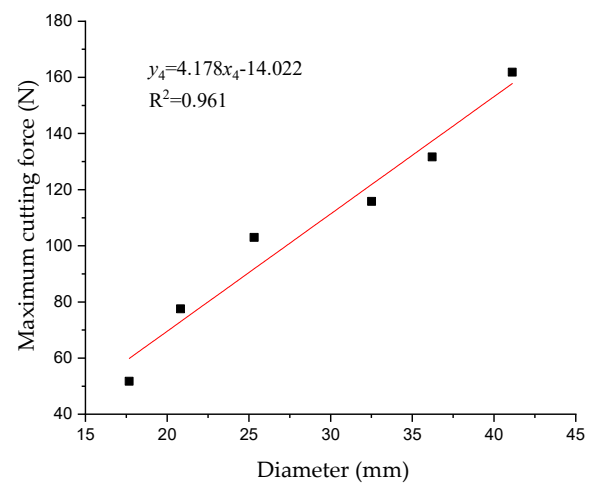

(b) Fitting function

Figure 10. Boxplot and fitting function of transverse maximum cutting force of jujube bark.

\section{Discussion}

\subsection{Effect of Growth Stress of Jujube Bark on Girdling}

The analysis results of the mathematical model of the growth stress of the jujube bark showed that the growth stress on the differential unit body of the jujube bark can be regarded as a biaxial stress state, and the growth stress of jujube bark near the ground is the largest. Therefore, when girdling, if the jujube bark is subjected to tangential cutting resistance and growth stress $\sigma_{2}$, which are greater than the transverse tensile strength of the bark, the jujube bark will be not cut but torn along its fiber direction. If the resultant force along the bark fiber direction produced by girdling and growth stress $\sigma_{1}$ is greater than the tensile strength of jujube bark, the bark will be pulled apart rather than cut off. That is to say, this growth stress of jujube bark can promote the breaking and tearing of bark fibers during girdling. So, this result is consistent with the previous hypothesis made in the introduction.

In addition, because the trunk near the ground has the largest growth stress, in order to reduce the adverse impact of growth stress on girdling, girdling of the trunk near the ground should be avoided as much as possible. Therefore, the primary branch can be selected to be girdled in order to reduce the bark tearing problem. Furthermore, as the effect of growth stress on the girdling of jujube was only qualitatively analyzed in this study, in order to further explore the quantitative influence law of growth stress on the fruit tree girdling process, more in-depth research on this problem will be needed in the future.

\subsection{Effect of Mechanical Properties of Jujube Bark on Girdling}

The results of the longitudinal tensile test of jujube bark showed that the maximum load range was 105.9 293.1 N, the average tensile strength was $16.3 \mathrm{MPa}$ and the elastic modulus was $255.6 \mathrm{MPa}$. However, what the transverse tensile test results showed was that the average transverse tensile load was only $27.9 \%$ of that of the longitudinal tensile test. Therefore, during girdling, jujube bark is more likely to be torn along the fiber direction rather than cut off, resulting in poor quality of girdling and difficult-to-heal wounds. Furthermore, the results of transverse cutting load test of the jujube bark showed that the average cutting force was $118.2 \mathrm{~N}$ and the cutting strength was $9.8 \mathrm{MPa}$. Moreover, both the tensile and cutting forces of bark were positively correlated with its thickness. Based on the above research results of jujube bark, attention should be paid to the selection of appropriate girdling tools and correct girdling operation methods. In order to reduce the tearing of jujube bark during girdling, appropriate cutting tools should be selected. Research in the literature $[30,31]$ showed that a blade with a serrated edge can easily cut off agricultural materials with low power consumption, but it can also easily cause irregular incisions. In the existing girdling tools, although most fruit farmers use blades with smooth edges, some farmers still use blades with serrated edges for rapid girdling. During girdling, blades with smooth edges have a weak ability to pierce the bark, and they also have a weak 
effect on the tearing of the bark. Therefore, blades with serrated edges shall be selected as much as possible.

In addition, during the girdling operation, if the blade starts to rotate around the bark without piercing the phloem, the blade will exert greater lateral resistance on the bark surface; this is not conducive to the quality of girdling. Therefore, first ensure that the blade penetrates into the phloem, and then slowly rotate the blade for continuous cutting. Because both the tensile and cutting forces of bark are positively correlated with its thickness, in order to ensure the quality of girdling, the appropriate force should be selected according to the size of the tree. Furthermore, in order to promote the healing of the girdling wound $[32,33]$, the wound should be bandaged with plastic in time. Because this work is troublesome, only a few fruit farmers undertake this at present. However, in order to reduce the water loss and the harm of diseases and pests, protect the phloem and promote its rapid healing; this measure should be widely taken.

Considering the special mechanical properties of jujube bark, we should pay attention to the research and development of special blades for girdling. Firstly, materials with high wear resistance and hardness should be selected. For example, $2 \mathrm{Cr} 13$ with boronizing and vanadizing treatment can be used to improve their cutting effects and wear resistance [34]. Secondly, for the blade's structural design, we should try to reduce the blade angle, increase the cutting angle, and then reduce the cutting resistance [35]. Besides, the bionic principle can be used to optimize the structure and function of the blade, and reduce the adhesion of debris to the blade to improve the cutting effect [36]. Finally, due to the irregular crosssectional shape of the trunk, it is easy for part of the bark to not be cut or part of the xylem to be removed when girdling, which affects the girdling quality. Therefore, in order to make the girdling knife cut the phloem smoothly without damaging the xylem, the girdling device should be designed with a profile function.

\section{Conclusions}

In the present study, aimed at the hypothesis that the physical and mechanical characteristics and growth stress distribution of jujube bark have adverse effects on the jujube girdling, and to find out how they affect the tearing of jujube bark in girdling process, the mechanical characteristics of jujube bark were tested and the growth stress model was built. The analysis results of the mechanical model of the growth stress of jujube bark showed that growth stress can promote the breaking and tearing of bark fibers during girdling. Furthermore the mechanical test results indicated that the transverse tensile load is much smaller than the longitudinal tensile force. In other words, during girdling, jujube bark is more likely to be torn along the fiber direction rather than cut off. So, we can conclude that both the growth stress and the anisotropic natural polymer of jujube bark have adverse effects on girdling. To the best of our knowledge, this is the first time that the effects of growth stress and the mechanical characteristics of jujube bark on the jujube girdling process were researched. Subsequently, the selection of the appropriate girdling tool and the matters that required attention in the process of the girdling operation were discussed, so as to guide the correct application of girdling technology. In addition, some suggestions on the research and development of girdling tools in the future were put forward.

Author Contributions: Resources, X.W.; data curation, F.Z.; writing-original draft preparation, J.R. and C.H.; writing-review and editing, C.H. and P.L.; visualization, F.Z.; supervision, X.W.; project administration, X.W. and P.L. All authors have read and agreed to the published version of the manuscript.

Funding: This work was supported by financial scientific and technological projects of Xinjiang Construction Corps, grant number 2021CB018; The innovative research project of Tarim University President Foundation, grant number TDZKSS202112; The innovative research project of Tarim University President Foundation, grant number TDZKCX202103.

Institutional Review Board Statement: Not applicable.

Informed Consent Statement: Not applicable. 
Data Availability Statement: The data presented in this study are available on request from the corresponding author.

Acknowledgments: This work was supported by financial scientific and technological projects of Xinjiang Construction Corps (Project No. 2021CB018), the innovative research project of Tarim University President Foundation (Project No. TDZKSS202112) and the innovative research project of Tarim University President Foundation (Project No. TDZKCX202103). The authors are grateful to the anonymous reviewers for their comments.

Conflicts of Interest: The authors declare no conflict of interest.

\section{References}

1. Yuan, H.; Wang, J.L.; Yuan, H. Quality evaluation of Xinjiang jujube based on principal component analysis and cluster analysis. Food Ind. 2020, 41, 305-309.

2. He, W.Z.; Zhao, D.Y.; Fan, Y.Y.; Wang, C.; Liu, Z. Comparison of the Nutrient Quality, Stable Isotope and Multi-Element Characteristics of Xinjiang Jujube for Origin Traceability. J. Nucl. Agric. Sci. 2021, 35, 1099-1112.

3. Zhao, A.L.; Xue, X.F.; Ren, H.Y.; Wang, Y.K.; Ling, D.K.; Ling, Y. Analysis of composition and content characteristics of organic acids in Jujube germplasm. Acta Agric. Boreali-Occident. Sin. 2021, 30, 1185-1198.

4. Guan, Q.L. Study on the Potential and Strategy to Develop Jujube in Xinjiang Province. Master's Dissertation, Huazhong Agricultural University, Wuhan, China, 2010.

5. Liu, C. Studies on Functional Components and Processing Technology of Xinjiang Jujube Dates. Master's Dissertation, Zhejiang University, Hangzhou, China, 2014.

6. Jiao, B.Z.; Sun, Z.J.; Han, L.; He, J. Effects of depth and irrigation amount of subsurface infiltration irrigation pipes on water use efficiency and yield of jujube. Trans. CSAE 2020, 36, 94-105.

7. Xu, H.B.; Feng, J.C.; Fan, L.L. Research progress on girdling mechanism and non-invasive girdling technology of pomiculture. J. Henan Agric. Sci. 2020, 49, 1-9.

8. Khandaker, M.M.; Hossain, A.S.; Osman, N. Application of girdling for improved fruit retention, yield and fruit quality in Syzygium samarangense under field conditions. Int. J. Agric. Biol. 2011, 13, 18-24.

9. Deschepper, V.; Steppe, K. Tree girdling responses simulated by a water and carbon transport model. Ann. Bot. 2011, 108, 1147-1154. [CrossRef]

10. Pelletier, M.G.; Wanjura, J.D.; Holt, G.A. Chemical-free cotton defoliation by: Mechanical, flame and laser girdling. Agronomy 2017, 7, 9. [CrossRef]

11. Urban, L.; Alphonsout, L. Girdling decreases photo-synthetic electron fluxes and induces sustained photo-protection in mango leaves. Tree Physiol. 2007, 27, 345-352. [CrossRef]

12. Quentin, A.G.; Close, D.C.; Hennen, L.M. Down-regulation of photosynthesis following girdling, but contrasting effects on fruit set and retention, in two sweet cherry cultivars. Plant Physiol. Bio-Chem. 2013, 73, 359-367. [CrossRef]

13. Choi, S.T.; Song, W.D.; Park, D.S. Effect of girdling dates on dry matter increase and reserve accumulations in permanent parts of 'Nishimurawase' persimmon trees. Korean J. Hortic. Sci. Technol. 2009, 27, 18-225.

14. Tombesi, S.; Dayk, R.; Johnson, R.S. Vigour reduction in girdled peach trees is related to lower midday stem water potentials. Funct. Plant Biol. 2014, 41, 1336-1341. [CrossRef] [PubMed]

15. Williams, L.E.; Retzlaff, W.A.; Yang, W.G. Effect of girdling on leaf gas exchange, water status, and nonstructural carbohydrates of field-grown Vitis vinifera L. (cv. flame seedless). Am. J. Enol. Vitic. 2000, 51, 49-54.

16. Yang, J.; Zhang, Y.H.; Gao, F.L. Effects of species and habit on quality in Zizyphus jujuba date and quality assessment. Food Sci. Technol. 2021, 35, 143-145.

17. Hamant, O.; Traas, J. The mechanics behind plant development. New Phytol. 2010, 185, 369-385. [CrossRef] [PubMed]

18. Boudaoud, A. An introduction to the mechanics of morphogenesis for plant biologists. Trends Plant Sci. 2010, 15, 353-360. [CrossRef]

19. Yan, Z. The Characteristic of Larix Gmelini Bark Pyrolysis and the Preparation of Pyrolysate Adhesive. Master's Thesis, Beijing Forestry University, Beijing, China, 2006.

20. Gindl, W. The effect of lignin on the moisture-dependent behavior of spruce wood in axial compression. J. Mater. Sci. Lett. 2001, 20, 2161-2162. [CrossRef]

21. Gong, M.; Smith, I. Effect of load type on failure mechanisms of spruce in compression parallel to grain. Wood Sci. Technol. 2004, 37, 435-445. [CrossRef]

22. Gindl, W.; Teischinger, A. Axial compression strength of Norway spruce related to structural variability and lignin content. Compos. Part A Appl. Sci. Manuf. 2002, 33, 1623-1628. [CrossRef]

23. Feng, H.J.; Feng, L.; Kang, Y.L. Mechanics and modeling of crack formation in tree epidermis. Acta Biophys. Sinica. 2011, 27, 779-788.

24. Biechele, T.; Nutto, L. Growth stress in Eucalyptus nitens at different stages of development. In Proceedings of the 51st International Convention of Society of Wood Science and Technology, Concepcion, Chile, 12 November 2008; pp. 10-12.

25. Luo, Z.D.; Li, S.J. Anisotropic Material Mechanics; Shanghai Jiao Tong University Press: Shanghai, China, 1994. 
26. Liao, Y.T.; Liao, Q.X.; Tian, B.P.; Shu, C.X.; Wang, J.; Ma, A.L. Experimental research on the mechanical physical parameters of bottom stalk of the Arundo donax L. in harvesting period. Trans. CSAE 2007, 23, 124-129.

27. Liu, Z.P.; Xie, F.P.; Wu, M.L.; Wang, X.; Liu, J.F. Study of mechanical property parameters of ramie bottom stalk in harvesting period. J. Hunan Agric. Univ. Nat. Sci. 2011, 37, 329-332. [CrossRef]

28. Shen, C.; Li, X.W.; Tian, K.P.; Zhang, B.; Huang, J.C.; Chen, Q.M. Experimental analysis on mechanical model of ramie stalk. Trans. CSAE 2015, 31, 26-33.

29. Zhong, W.Z.; Deng, Z.F.; Huang, X.C.; He, Z.M. Investigation on anisotropic behavior of spruce mechanical properties under medium strain rate loading conditions. Eng. Mech. 2016, 33, 25-33.

30. Luo, H.; Tang, C.Z.; Zou, D.S. Experiment on reciprocating cutting of eulaliopsis binata stem. Trans. CSAE 2012, $28,13-17$.

31. Wu, M.L.; Guan, C.Y.; Tang, C.Z. Experiments on influencing factors of cutting force of rape stem. Trans. CSAE 2009, 25, 141-144.

32. Hamada, K.; Ogata, T.; Fujiwara, S.; Hasegawa, K. Healing process of the wounds of the branches of the Japanese persimmon that were caused by girdling, scoring, and strangulation. Sci. Hortic. 2009, 120, 276-281. [CrossRef]

33. Chano, V.; López, R.; Pita, P.; Collada, C.; Soto, Á. Proliferation of axial parenchymatic xylem cells is a key step in wound closure of girdled stems in Pinus canariensis. BMC Plant Biol. 2015, 15, 64. [CrossRef]

34. Wan, Q.; Zhu, F.T.; Liu, X.F. Changes in the microstructure and properties of the egg-break blade after boronisation and vanadizing. Trans. Chin. Soc. Agric. Eng. 2020, 36, 291-297.

35. Guo, Q.; Zhang, X.L.; Xu, Y.F. Design and experiment of cutting blade for cane straw. Trans. Chin. Soc. Agric. Eng. 2014, $30,47-53$.

36. Tian, K.P.; Li, X.W.; Shen, C.; Zhang, B.; Huang, J.C.; Wang, J.G.; Zhou, Y. Design and test of cutting blade of cannabis harvester based on longicorn bionic principle. Trans. Chin. Soc. Agric. Eng. 2017, 33, 56-61. 